\title{
The longitudinal trend of hypertension prevalence in Chinese adults from 1959 to 2018: a systematic review and meta-analysis
}

\author{
Mingyang Bao ${ }^{1,2}$, Lina Wang ${ }^{1}$ \\ ${ }^{1}$ Department of Epidemiology \& Biostatistics, Key Laboratory of Environmental Medicine Engineering, Ministry of Education, School of Public \\ Health, Southeast University, Nanjing, China; ${ }^{2}$ State Key Laboratory of Genetic Engineering, Institute of Biostatistics, School of Life Sciences, \\ Fudan University, Shanghai, China \\ Contributions: (I) Conception and design: All authors; (II) Administrative support: L Wang; (III) Provision of study materials or patients: All authors; \\ (IV) Collection and assembly of data: M Bao; (V) Data analysis and interpretation: All authors; (VI) Manuscript writing: All authors; (VII) Final \\ approval of manuscript: All authors. \\ Correspondence to: Lina Wang. Department of Epidemiology \& Biostatistics, Key Laboratory of Environmental Medicine Engineering, Ministry of \\ Education, School of Public Health, Southeast University, 87 Ding Jiaqiao Rd., Nanjing 210009, China. Email: lnwang@seu.edu.cn.
}

Backgrounds: Hypertension is one of the most prevalent non-communicable diseases (NCDs). However, unbalanced regional development and different research designs lead to greater heterogeneity of hypertension data in China, and lack of a summary of long-term variation trends. The aim was to estimate the pooled prevalence of hypertension and to describe the secular trend in hypertension.

Methods: Literatures, related to the prevalence of hypertension among Chinese adults, were searched through both English and Chinese databases. The pooled prevalence was estimated with random effects. Subgroup analysis and meta-regression was conducted to address heterogeneity. Continuous fractional polynomial regression model and compound model were used to estimate the trend of hypertension prevalence with time.

Results: A total of 18 studies were included and the whole population was 9, 191, 121. The pooled prevalence of hypertension among Chinese adults was 24.3\% (95\% CI: $18.8-29.8 \%$ ), increasing from the west to the east. Hypertension was more common in male than in female (27.8\% vs. 25.1\%) and in urban population than in rural population $(27.0 \%$ vs. $26.0 \%)$. The annual increase of prevalence was about $0.29 \%$ nonlinearly before 2004 and maintained approximately $2.45 \%$ per year between 2004 and 2010. After a significant decline in 2011, there was a slight incline.

Conclusions: The prevalence of hypertension in Chinese adults has been increasing, indicating that more efforts should be strengthened for hypertension management in China.

Keywords: Hypertension; prevalence; meta-analysis; fractional polynomial regression

Submitted Oct 15, 2019. Accepted for publication Jun 30, 2020.

doi: 10.21037/apm-19-377

View this article at: http://dx.doi.org/10.21037/apm-19-377

\section{Introduction}

Non-communicable diseases (NCDs) comprised the greatest fraction of deaths, accounting for $73.4 \%$ of total deaths in 2017, while high blood pressure was one of the leading risk factors for NCDs (1). In line with the global trend, the burden of hypertension has increased rapidly over the past decades in China. With the acceleration of
China's economic development and urbanization, the aging of the population and epidemic of obesity, hypertension has become one of the major public health problems, affecting the health of Chinese residents (2). Chinese scholars recently reported the latest large-scale population investigation of hypertension in Circulation (3), which has aroused widespread concern and discussion at home and abroad. According to the national survey, the prevalence of 
hypertension in Chinese adults reached 23.2\%. Compared with the second national hypertension prevalence survey in 1979 (4), the prevalence increased double. Chinese Guidelines for the Management of Hypertension (in 2018) pointed that the prevalence of hypertension in China was still on the rise, but there were some new changes in epidemic characteristics (5). Another national population-based screening study (China Patient-Centered Evaluative Assessment of Cardiac Events Million Persons Project) revealed the hypertension prevalence of population aged 35-75 reached $37.2 \%$ in 2014-2017 (6).

Due to the large population, estimation of prevalence will make contributions to evaluation of the scale of patients and cost of clinical treatment, as well as the allocation of public health resources. Concurrent with an epidemiological transformation of disease spectrum, government has taken actions to improve the chronic disease surveillance system and conduct a series of cross-sectional surveys $(7,8)$ and cohort studies $(9,10)$. The current literatures reporting the hypertension rate with more diversity populations, different representative, less power and without national trend of hypertension, so we conducted a systematic review and meta-analysis on the hypertension prevalence in the past sixty years and described the trend using the longitudinal data to assist in the planning and implementation of future management. We present the following article in accordance with the PRISMA Reporting Checklist (available at http://dx.doi.org/10.21037/apm-19-377).

\section{Method}

\section{Search strategy}

We searched for epidemiological studies on hypertension from several electronic databases, including PubMed, the China National Knowledge Infrastructure (CNKI), the Wanfang and Chongqing VIP. A systematic literature searching proceed was performed in the PubMed database with the MeSH terms "hypertension", "prevalence" and "China". Three Chinese databases were used to searching for Chinese papers with the keywords "hypertension", "prevalence" and "China". All the literatures were searched before September 20, 2019. In addition, the references listed in the literatures were also retrieved to seek more eligible articles. The English and Chinese papers were taken into consideration.

\section{Inclusion and exclusion criteria}

In order to achieve the goal of analysis and reduce selection deviation, studies were required to meet the following criteria:

(I) Description of the hypertension prevalence in mainland China;

(II) Using population-based epidemiological survey data;

(III) Clearly reporting research design, detection time, hypertension diagnosis methods and diagnostic criteria;

(IV) Baseline data for cohort study population;

(V) Following hypertension diagnostic criteria proposed by the World Health Organization/ International Society Hypertension (WHO/ISH) in 1999 (if the WHO/ISH 1978 criteria were used, the prevalence of borderline hypertension should be reported).

According to the WHO/ISH 1999 criteria (11), hypertension was defined as systolic blood pressure (SBP) $\geq 140 \mathrm{mmHg}$ and (or) diastolic blood pressure (DBP) $\geq 90 \mathrm{mmHg}$ and (or) use of antihypertensive medicine within 2 weeks. However, hypertension was defined when the blood pressure was up to $160 / 95 \mathrm{mmHg}$ and above; blood pressure between 160/95 and 140/90 $\mathrm{mmHg}$ was designated as 'borderline hypertension', as recommended by a WHO Expert Committee Meeting held in 1978 (12).

Studies were excluded if the following terms were met:

(I) Only pre-hypertension prevalence involved;

(II) Reporting the prevalence of hypertension combined with other chronic diseases;

(III) A specific population-based investigation: such as people of specific occupations, ethnic minorities, patients with certain diseases;

(IV) Case-control study;

(V) Secondary analysis, such as reviews, communications, reviews, reports, etc.;

(VI) Results already reported by other included studies; (VII) Study areas limited to a province or smaller.

\section{Literature screening}

All of articles collected from different electronic databases were combined in NoteExpress, and duplicates were removed. Then, two independent researchers screened titles and abstracts and reviewed full text of the eligible citations if title and abstract were not explicit enough to determine whether the inclusion criteria were met; disagreement over eligibility of studies was solved by all investigators. If more than one article reported the same research or detection 


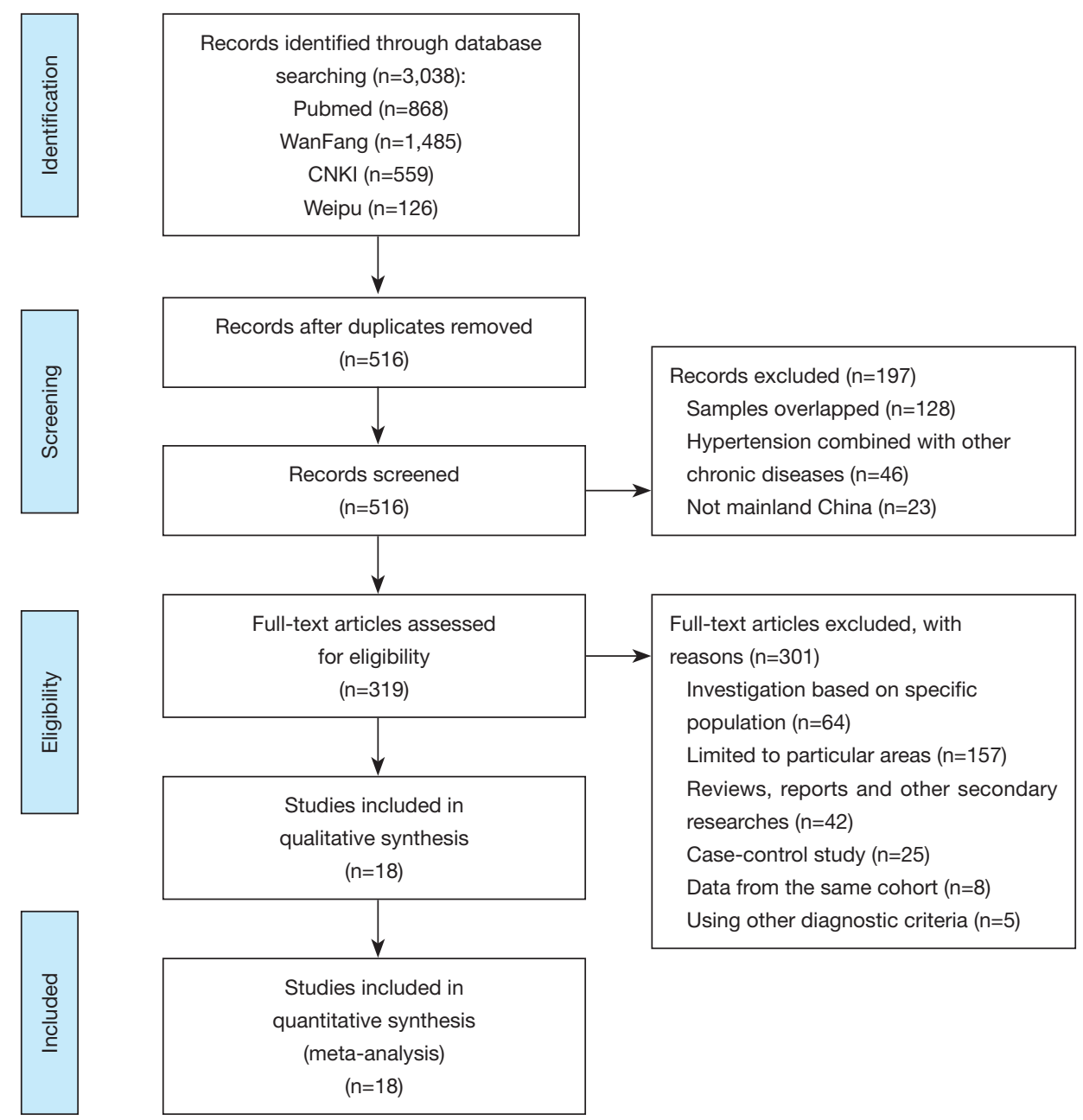

Figure 1 Flow diagram of selecting relevant studies.

time in the same year, we selected a more comprehensive one (Figure 1).

\section{Quality assessment}

The assessment of literature quality followed the observational study criteria that were recommended by the Agency of Healthcare Research and Quality (AHRQ) (13). The third investigator took part in discussion to reach a consensus when two reviewers made different assessments. The quality score of retained articles was at least 6 points.

\section{Data extraction and statistical analysis}

We extracted the key information from each included article: name of first author, screening year, publication year, study region, number of participants, age, gender, hypertension prevalence and 95\% confidence interval (CI), standardized population and diagnostic criteria. Prevalence of hypertension with $95 \%$ CI was pooled. Heterogeneity among studies was assessed with a forest plot and the inconsistency statistic $\left(\mathrm{I}^{2}\right)$. If there is no heterogeneity $\left(\mathrm{I}^{2} \leq 50 \%\right)$, the fixed-effect model was used for the metaanalysis; otherwise, the random-effect model was employed. Subgroup analysis was conducted based on the stratification of screening time, gender, geographical region, area, and age group. Some variables mentioned above were also included in a meta-regression. One of the studies was only included in the age group and geographic stratification analysis (14), because it was limited to population aged 35-85 and detection time coincided with another more comprehensive study. If hypertension prevalence changed with time and age significantly in case of heterogeneity across studies, we explored the trend in the further step. In 
order to reduce the confounding caused by age, 6 studies with aged $\geq 35$ years old were excluded. The continuous fractional polynomial regression model at the midpoint of each survey period was used to estimate the prevalence of hypertension over time. In addition, according to the age stratification in the subgroup analysis, the sigmoidal model based on the midpoint of each age group was used to estimate the trend of hypertension prevalence with age. Statistical analysis was performed using Stata 12.0 software (College Station, Texas), both for bilateral testing and reporting $95 \%$ CI. $\mathrm{P}<0.05$ was considered as significance level for all analysis.

Besides, sensitivity analysis was conducted to measure the effect of any study on the pooled estimate. Begg's test was performed to assess the publication bias.

\section{Results}

\section{Study selection and characteristics}

A total of 3,038 articles were obtained from the initial search, including 559 from CNKI, 1,485 from Wanfang, 126 from VIP, and 868 from PubMed. A total of 516 records were excluded after screening titles, abstracts and removing duplicate studies. After further reading the full text, 26 papers which reported the prevalence of hypertension in Chinese adults in mainland based on a nationwide sample survey ( $\geq 2$ provinces) were included. By retrieving references to these articles, two additional studies were included $(15,16)$. As for the remaining 28 relevant studies, 10 were excluded, 3 of which diagnostic criteria for hypertension adopted the definition recommended by WHO/ISH in 1978 but did not report the prevalence of borderline hypertension. The investigation region of another 7 excluded studies was restricted to a specific area, so the results could not represent the national level. A total of 18 studies provided comprehensive information on the prevalence of hypertension and included in the final analysis. The flow diagram of the studies selection process was shown in Figure 1. The prevalence of hypertension and the characteristics of research reported in the literatures were summarized in Table 1.

The baseline information of overall studies was collected from 1959 to 2017. Among the 18 included studies, 9 were included all provinces (autonomous regions and municipalities) in mainland China; 2 were prospective cohort studies and 16 were cross-sectional surveys; 6 were written in Chinese and 12 were written in English;
6 were limited to respondents aged $\geq 35$ years. The total sample size of the involved studies was $9,191,121$. The diagnostic criteria for hypertension mainly corresponded to the WHO/ISH 1999 criteria (WHO/ISH has not changed the definition of hypertension since 1999; the multiple versions of Chinese Guidelines for the Management of Hypertension have also adopted the criteria). The first national hypertension prevalence survey did not clarify diagnostic criteria; the second national survey adopted the WHO/ISH 1978 criteria and the prevalence including both defined hypertension and borderline hypertension was used in accordance with other studies. As to quality assessment, three of studies scored 6; another 15 articles scored between 7 and 10 .

\section{Prevalence of hypertension and subgroup analysis}

In general, the prevalence of standardized hypertension varied between $5.11 \%$ and $37.2 \%$ from 1959 to 2017 . The pooled prevalence of hypertension among Chinese adults was $24.3 \%$ (95\% CI: $18.8-29.8 \%$ ) (Figure 2) and there was significant heterogeneity of the selected studies due to diverse sources of population $\left(\mathrm{I}^{2}=100.0 \%, \mathrm{P}<0.001\right)$.

In the subgroup analysis, the pooled prevalence of hypertension was stratified by the midpoint of detection year, sex, geographical region, area and age group. As shown in Table 2, the pooled prevalence from 2006 to 2015 was higher than that from 1979 to 2004. There were 14 articles reported the prevalence of hypertension by gender. As a result, the pooled prevalence in males was $2.7 \%$ higher than that of females. Next, six articles reported the prevalence of hypertension in terms of different geographical regions. Consequently, the prevalence rose from the west to the east. Then, 12 articles reported the prevalence in different regions. Residents living in urban areas $(27.0 \%, 95 \% \mathrm{CI}$ : $19.2-34.8 \%)$ were more likely to suffer from hypertension than those living in rural areas $(26.0 \%, 95 \%$ CI: $15.9-$ $36.2 \%)$. Additionally, six articles reported the prevalence of hypertension by age group. With the increase of age, more people suffered hypertension.

\section{Meta-regression}

Given that both overall and subgroup analysis revealed a high level of heterogeneity $\left(\mathrm{P}<0.001, \mathrm{I}^{2}=99.9 \%\right)$, metaregression analysis was performed. In the univariate analyses, the variables of age range, detection time and publication time were significantly associated with 


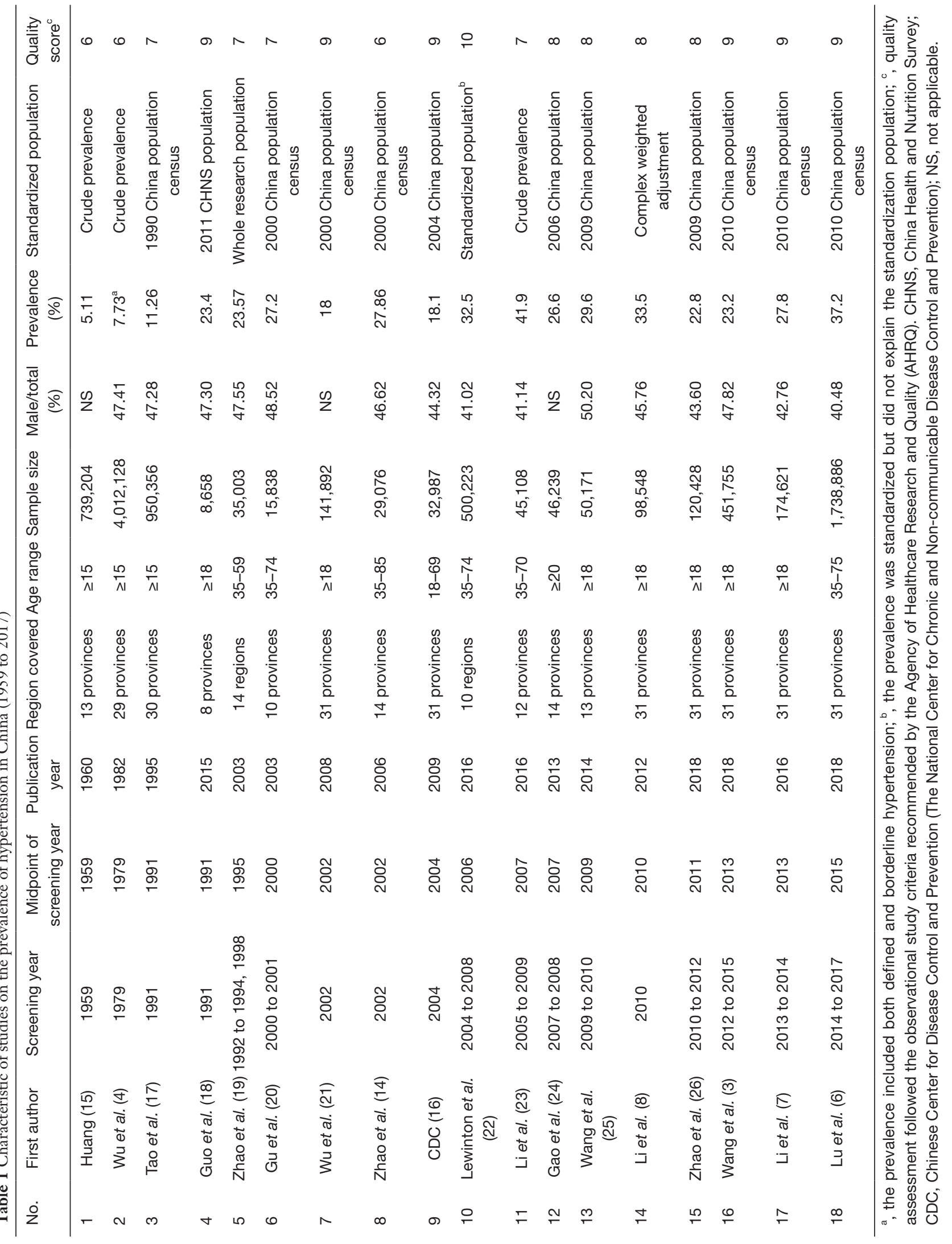




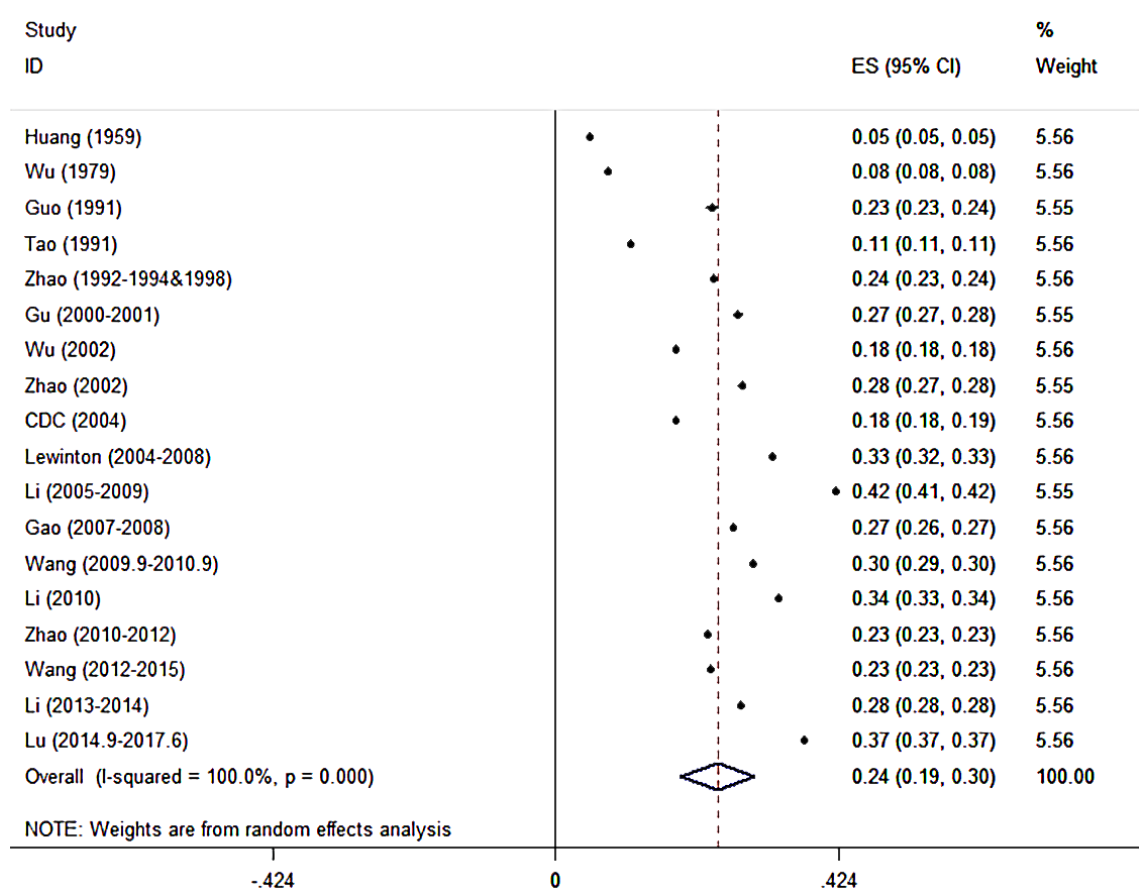

Figure 2 Forest plot of the hypertension prevalence in Chinese adults in the random-effects model.

Table 2 Stratified analysis on the prevalence of hypertension in China (1959 to 2017)

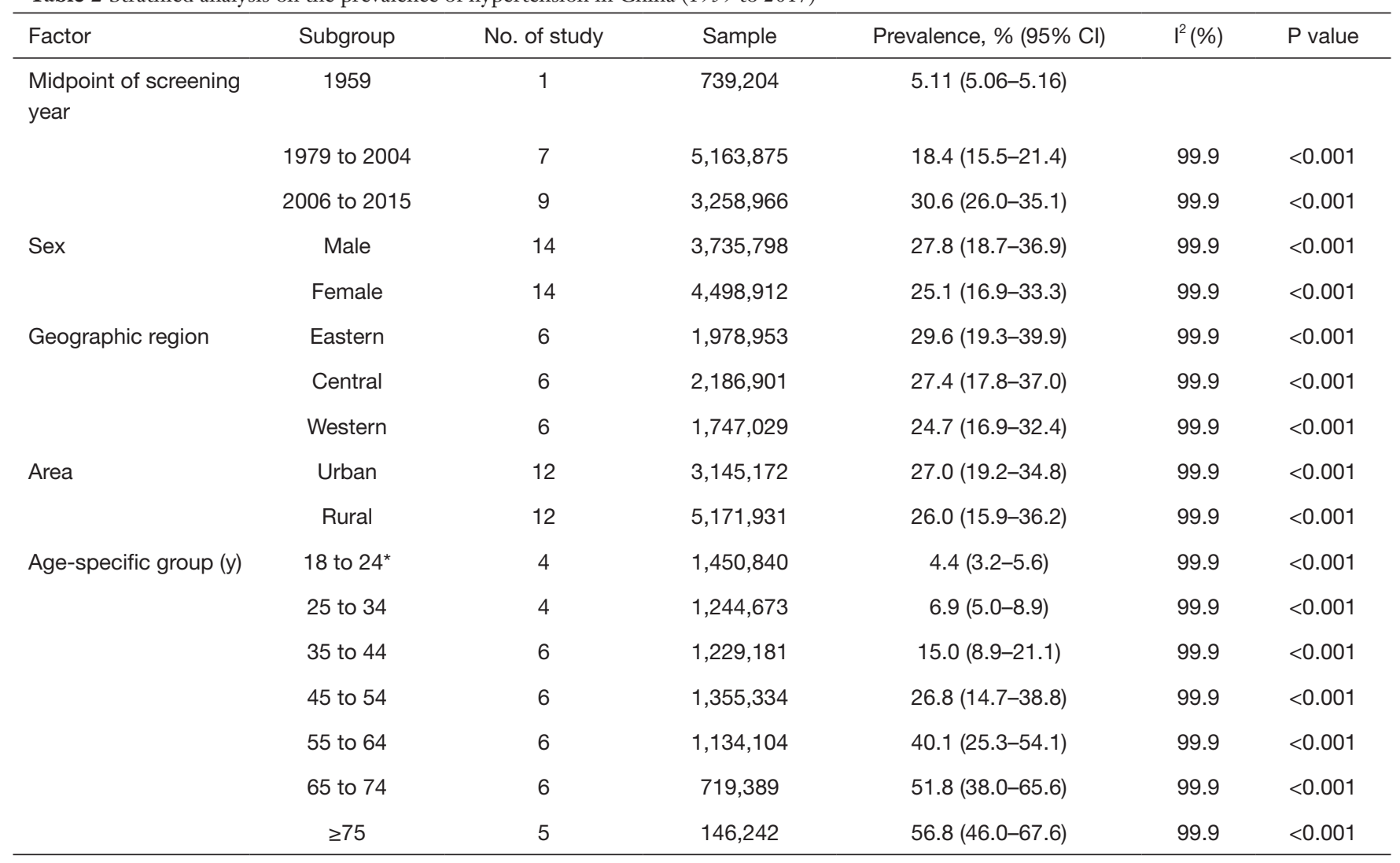

*, age-specific group of studies (4) and (15) is 15-24. 
Table 3 Results of meta-regression for the prevalence of hypertension in China (1959 to 2017)

\begin{tabular}{lcccc}
\hline Covariance & Meta-regression coefficient & $95 \% \mathrm{Cl}$ & $\mathrm{P}$ value & Proportion of variance explained (\%) \\
\hline Univariate analyses & & & & \\
Year of screening & 0.0053 & $0.003-0.008$ & $<0.001$ & 56.87 \\
Year of publication & 0.0050 & $0.003-0.008$ & $<0.001$ & 58.49 \\
Male/total (\%) & -0.0157 & -0.032 to 0.000 & 0.054 & 21.44 \\
Age range* & 0.1189 & $0.023-0.215$ & 0.019 & 27.05 \\
Quality score & 0.0378 & -0.004 to 0.079 & 0.073 & 14.60 \\
Multivariable analyses & & & 0.002 & 74.87 \\
Year of publication & 0.0080 & $0.004-0.012$ & 0.002 & 0.559 \\
Male/total (\%) & -0.0032 & -0.015 to 0.009 & 0.034 \\
Age range & 0.0747 & $0.007-0.143$ & 0.151 \\
Quality score & -0.0286 & -0.070 to 0.013 & \\
\hline
\end{tabular}

*, studies restricted to people aged $\geq 35$ years $=2$, others $=1$.

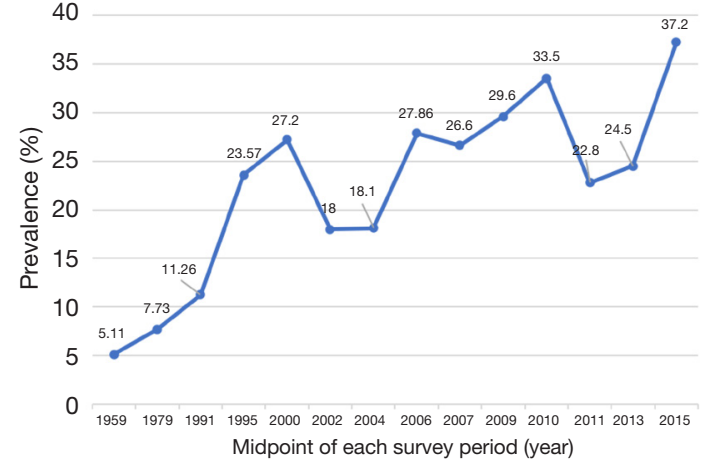

Figure 3 The long-term trend of hypertension prevalence in Chinese adults. Each dot represents the prevalence of hypertension in each study.

heterogeneity $(\mathrm{P}=0.019$ for age range, $\mathrm{P}<0.001$ for detection time, $\mathrm{P}<0.001$ for publication time, respectively). Because the variables-detection time and publication timeoverlapped when interpreting heterogeneity, only the later variables incorporated the multivariable analysis. The multivariable analysis showed a consistent result to the univariate analyses (Table 3).

\section{Prevalence of bypertension over time}

As shown in Figure 3, the prevalence of hypertension increased about 7 times, from $5.11 \%$ in 1959 to $37.2 \%$ in 2015 . The prevalence in 10-year age groups showed

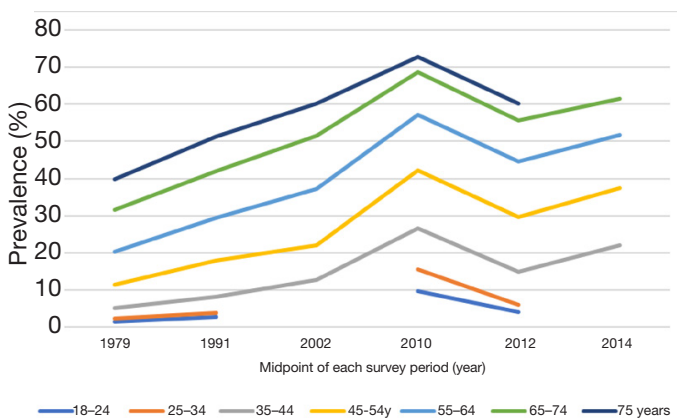

Figure 4 The long-term trend of hypertension prevalence in 10 -year age groups. Each colorful line represents an age group.

an accordant trend over time (Figure 4). Furthermore, continuous fractional polynomial regression model on the midpoint of screening year was used to estimate and illustrate the secular trend of the hypertension prevalence. Figure 5 showed the overall increase in the prevalence of hypertension was divided into two stages after six studies restricted to people aged $\geq 35$ years were excluded. The average annual increase of the prevalence was approximately 0.29\% before 2004; Between 2004 and 2010, the prevalence increased linearly by about $2.45 \%$ per year, about 8 times compared with the growth rate before 2004. The trend of hypertension prevalence changed within the second stage if including three latest studies (Figure 6). The compound model weighted by the sample size of each study was used to estimate the overall trend (Figure 7). In contrast with 


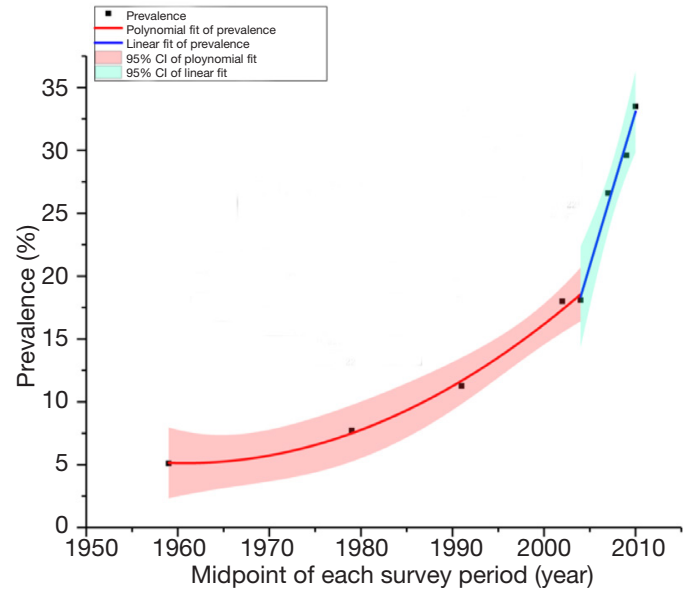

Figure 5 The prevalence of hypertension in Chinese adults increased over time before 2010. Divided into two segments by 2004, the polynomial fitting indicated by the red curve is the growth trend before 2004, and the linear fitting represented by the blue line is the growth trend after 2004.

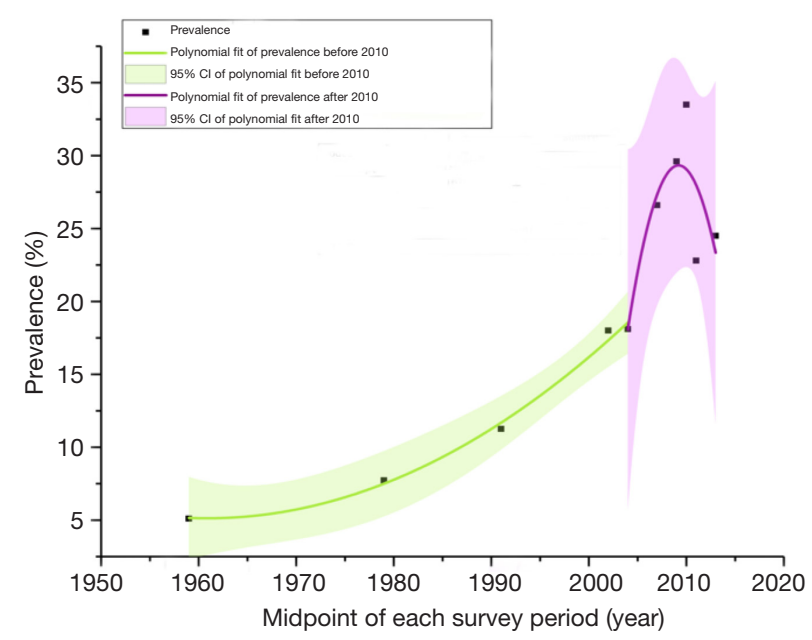

Figure 6 The trend of hypertension prevalence in Chinese adults over time. Divided into two segments by 2004, the previous polynomial fitting indicated by the green curve is the trend before 2004, and the latter polynomial fitting represented by the purple curve is the trend after 2004.

the posture shown in Figure 6, the prevalence maintained a continuous increase.

\section{Sensitivity analysis and publication bias}

According to the sensitivity analysis, 18 studies were evenly

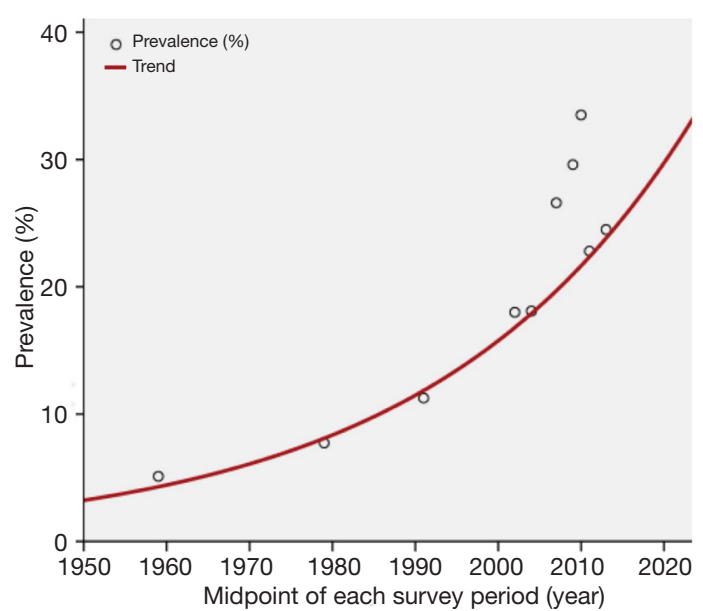

Figure 7 The overall posture of the long-term trend of the hypertension prevalence in Chinese adults since 1950. Each circle represents the prevalence of hypertension in each study. Red curve indicates the growth trend of hypertension prevalence.

distributed on both sides of the pooled hypertension prevalence (from $23.2 \%$ to $25.4 \%$ ). The results of sensitivity analysis did not conflict with that of original analysis, which strengthened the credibility of the original analysis results. In addition, all eighteen eligible studies yielded a Begg's test score of $\mathrm{P}=0.537$ which suggested the absence of publication bias.

\section{Discussion}

Totally, 18 articles were included in this study. Meta-analysis and continuous fractional polynomial regression analysis were used to describe the prevalence of hypertension in Chinese adults from 1959 to 2017. It showed that the pooled prevalence of hypertension from 1959 to 2017 was $24.3 \%$ and was increasing in two stages. The growth rate before 2004 was flat, and accelerated between 2004 and 2010. There was a slight increase after a significant decline in 2011. From the perspective of the whole trend, the prevalence reached a peak in 2010. However, the national chronic disease surveillance, conducted in 2010, did not clearly define that those who received antihypertensive treatment or antihypertensive drugs in the past two weeks were patients with hypertension (8). Therefore, it was likely that those with transient hypertension or blood pressure fluctuations around threshold were included in patients with hypertension, which overestimated the prevalence in 
2010. Secondly, a complex weighted approach was used to deal with the crude prevalence, so the reported prevalence was different from the standardized prevalence according to the 2010 Chinese population census. In addition, geographical and age distributions, sampling methods and blood pressure measurements were heterogeneous. All above mentioned may cause the peak of the prevalence in 2010 to be an illusion. According to the crude prevalence reported by six large national surveys from 1959 to 2015, the prevalence of hypertension has maintained a sustainable increase (5). According to China Health and Nutrition Survey (CHNS), the fluctuation of hypertension prevalence was not statistically significant between 2006 and 2011 (18). It could be inferred that the prevalence of hypertension was downshifting from a sustainably fast pace during this period.

In the subgroup analysis, we discovered that the prevalence of hypertension in urban areas was higher than in rural areas $(28.0 \%$ vs. $27.0 \%)$, a result that was in line with the previous findings $(27,28)$. Indeed, the difference between urban and rural areas was gradually shrinking. The latest national survey showed that the weighted prevalence of hypertension in rural and urban areas was similar, and the crude prevalence in rural areas was even higher than in urban areas (3). It suggested medical resources are deficient and many elderly people with low health literacy are staying behind in rural areas, which should be focused on in the next stage of hypertension management. Meanwhile, another trend that the prevalence gradually increases from west to east was also significant. The highest prevalence of hypertension was mainly concentrated in the eastern metropolis including Beijing (35.9\%) and Tianjin (34.5\%) (3). Additionally, this meta-analysis revealed that hypertension was more common in male than in female (27.8\% vs. $25.1 \%$ ), which was also found in East and South Asia (29-32). It was also important to be noted that age was a strongest determinant of the suffering of hypertension as both subgroup analysis and meta regression reflected. After age stratification, we could see that the trend over time presented a same pattern.

Distribution of hypertension showed regional imbalance and it is becoming more and more prevalent in other developing countries as well. Several studies reported a high prevalence of hypertension in Malaysia (32.7\%), Brazil (22.8\%), Turkey (24.8\%), India (25.8\%) and Arab countries (29.5\%) (29,30,33-35). The prevalence of hypertension had risen rapidly in most of these low- and middle-income countries (36-38). For example, there had been a constant
$12 \%$ increase every year in hypertension prevalence from the period of 1970 to 2014 in Brazil (38).

Global systematic analysis indicated the absolute burden was greatest among the middle-aged in low- and middleincome countries (39). Consistently, chronic disease surveillance in developing countries reported that the prevalence increased more sharply in the middle-aged population $(36,40,41)$, which suggested the early onset of hypertension. The findings of our study also confirmed this point.

However, the time-related trend in developing countries was different from that in more developed countries. The prevalence of male hypertension in Japan decreased from $54.2 \%$ to $50.1 \%$ from 1980 to 2010 , while that of female decreased significantly from $47.4 \%$ to $37.8 \%$ (31). In South Korea, the prevalence of hypertension in male decreased from $33.3 \%$ to $30.3 \%$ from 1998 to 2014 , while in female dropped significantly from $28.7 \%$ to $22.7 \%$ (32). Unlike the sustainable decline in Asian developed countries, the prevalence of hypertension in the United States maintained at around 30\% between 1999 and 2012 (29.3-31.1\%) (42), while in England increased slightly from 29.6\% in 1998 to $30 \%$ in $2006(43,44)$.

Over the past decades, China's economic reform has accelerated the process of urbanization (45). According to the sixth national census in 2010, half of China's population was living in urban areas. Although population aging and lower diagnostic criteria for hypertension since 1999 partly explain the increased prevalence of hypertension $(46,47)$, urbanization is the main causation. Lifestyles of citizens have changed drastically (48). Most of residents have been increasingly exposed to risk factors related to chronic diseases, such as bad living habits, environmental pollution, occupational stress and other social pressures (49). There is no doubt that the urbanization process has led to an increasing proportion of people who are overweight and obese, driving the growth of hypertension (50). In 2014, the male obese population increased 60 times compared with 1975, while women increased 27 times, both surpassing the United States and ranking first in the world (51). Data from the National Health and Nutrition Examination Surveys (NHANES) revealed that the proportion of obese people in all age groups was increasing (52). Especially in the age group $\leq 45$ years, the percentage of people with body mass index $(\mathrm{BMI})>30$ had exceeded $60 \%$, indicating that hypertensive population was becoming younger mainly because of obesity. A prospective study based on Chinese 
population demonstrated that with the increase of BMI, the relative risk for the incidence of hypertension in overweight and obesity groups was 1.16 to 1.28 compared with the normal weight group (53). A comparative study of risk factors for hypertension between the United States and Japan showed that for every $1 \mathrm{~kg} / \mathrm{m}^{2}$ increase in BMI, the odds ratio of developing hypertension in Japan increased by $23 \%$, which was about 4 times that of Americans (54). Obviously, Chinese and Japanese are more similar in many aspects such as food culture, so the incidence of hypertension is more sensitive to the increase in BMI. If the growth rate of BMI does not slow down, the prevalence of hypertension in China is likely to keep a continuous increase.

Our study incorporated national surveys on the prevalence of hypertension, with a large sample size and national representation, which eliminated geographical differences due to limitations of the scope of surveys. Moreover, this article was able to reflect the longitudinal trend because of a long-time span-nearly sixty years.

Nevertheless, some shortcomings should be noted. Firstly, the current meta-analysis revealed a high heterogeneity, which possibly resulted from differences in sampling methods and sample sizes among studies. Due to the lack of raw material, many factors correlated with heterogeneity have not been included in subgroup analysis and meta-regression. Therefore, the explanation of heterogeneity is not complete. Secondly, advance in blood pressure measurement from mercury to digital sphygmomanometers has effects on diagnostic criteria. Improved accuracy of measurements is likely to accelerate the evolutionary results of blood pressure. Moreover, the eligible published articles before the 1990s was so limited that the time interval among the included articles was discordant. Last, the prevalence of hypertension after 2010 declined by about $10 \%$ compared with that of 2010 , even lower than that between 2006 and 2010. Yet, the overall trend estimated by compound model revealed sustained growth. In addition, it is not convinced that the prevalence reached a peak in 2010 according to Chinese Guidelines for Management of Hypertension $(5,55)$.

\section{Conclusions}

In conclusion, the prevalence of hypertension in Chinese adults has continued to increase over the past sixty years. In the subgroup, the prevalence of hypertension is higher in male, the elderly, and overweight and obese people.
Given rapid economic development, the rising trend of the prevalence of hypertension will maintain in the future. Moreover, with a large population, there is still a long way to go to reach a balance of development between different regions in China. Therefore, different strategies should be conducted when implementing management of hypertension. In rural areas, priority should be given to health education and health screening in order to detect hypertension earlier, and in urban areas, healthy lifestyles of the population should be cultivated to reduce exposure to the risk factors of the hypertension.

\section{Acknowledgments}

The authors thank Mr. Nathan Obore for his help with polishing the article.

Funding: This study was partly supported by the National Natural Science Foundation of China (81673259), Natural Science Foundation of Jiangsu Province, China (BK20161435), English Excellent Course Construction Project of Southeast University (2019 No.110: Evidence Based Medicine).

\section{Footnote}

Reporting Checklist: The authors have completed the PRISMA Reporting Checklist. Available at http://dx.doi. org/10.21037/apm-19-377

Conflicts of Interest: All authors have completed the ICMJE uniform disclosure form (available at http://dx.doi. org/10.21037/apm-19-377). The authors have no conflicts of interest to declare.

Etbical Statement: The authors are accountable for all aspects of the work in ensuring that questions related to the accuracy or integrity of any part of the work are appropriately investigated and resolved.

Open Access Statement: This is an Open Access article distributed in accordance with the Creative Commons Attribution-NonCommercial-NoDerivs 4.0 International License (CC BY-NC-ND 4.0), which permits the noncommercial replication and distribution of the article with the strict proviso that no changes or edits are made and the original work is properly cited (including links to both the formal publication through the relevant DOI and the license). See: https://creativecommons.org/licenses/by-nc-nd/4.0/. 


\section{References}

1. GBD 2017 Causes of Death Collaborators. Global, regional, and national age-sex-specific mortality for 282 causes of death in 195 countries and territories, 1980-2017: a systematic analysis for the Global Burden of Disease Study 2017. Lancet 2018;392:1736-88.

2. Bundy JD, He J. Hypertension and related cardiovascular disease burden in China. Ann Glob Health 2016;82:227-33.

3. Wang Z, Chen Z, Zhang L, et al. Status of hypertension in China: results from the China Hypertension Survey, 20122015. Circulation 2018;137:2344-56.

4. Wu YK, Lu CQ, Gao RC, et al. Nation-wide hypertension screening in China during 1979-1980. Chin Med J (Engl) 1982;95:101-8.

5. Liu LS. Chinese guidelines for the management of hypertension (revised edition in 2018). Beijing: People's Medical Publishing House, 2018.

6. Lu J, Lu Y, Wang X, et al. Prevalence, awareness, treatment, and control of hypertension in China:data from 1.7 million adults in a population-based screening study (China PEACE Million Persons Project). Lancet 2017;390:2549-58.

7. Li Y, Yang L, Wang L, et al. Burden of hypertension in China: a nationally representative survey of 174,621 adults. Int J Cardiol 2017;227:516-23.

8. Li YC, Wang LM, Jiang Y, et al. Prevalence of hypertension among Chinese adults in 2010. Zhonghua Yu Fang Yi Xue Za Zhi 2012;46:409-13.

9. Chow CK, Teo KK, Rangarajan S, et al. Prevalence, awareness, treatment, and control of hypertension in rural and urban communities in high-, middle-, and low-income countries. JAMA 2013;310:959-68.

10. Popkin BM, Du S, Zhai F, et al. Cohort Profile: the China Health and Nutrition Survey--monitoring and understanding socio-economic and health change in China, 1989-2011. Int J Epidemiol 2010;39:1435-40.

11. 1999 World Health Organization-International Society of Hypertension Guidelines for the Management of Hypertension. Guidelines Subcommittee. J Hypertens 1999;17:151-83.

12. Arterial hypertension: report of a WHO expert committee. World Health Organization Technical Report Series 1978. Available online: https://apps.who.int/iris/ handle/10665/41632

13. Rostom A, Dubé C, Cranney A, et al. Celiac disease. Evid Rep Technol Assess (Summ) 2004;(104):1-6.

14. Zhao XL, Chen J, Cui YL, et al. Current status of primary hypertension in China: an epidemiological study of 12 provinces, 1 autonomous region, and 1 municipality. Zhonghua Yi Xue Za Zhi 2006;86:1148-52.

15. Huang JS. The summary report of the National Symposium on Heart and Vascular Diseases. The Collection of Scientific Reports on the National Symposium on Heart and Vascular Diseases. Beijing: People's Publishing House, 1960.

16. Chinese Center for Disease Control and Prevention (The National Center for Chronic and Non-communicable Disease Control and Prevention). 2004 Report on Chronic Disease Risk Factor Surveillance in China. Beijing: Peking Union Medical College Press (China), 2009.

17. Tao S, Wu X, Duan X, et al. Hypertension prevalence and status of awareness, treatment and control in China. Chin Med J (Engl) 1995;108:483-9.

18. Guo J, Zhu YC, Chen YP, et al. The dynamics of hypertension prevalence, awareness, treatment, control and associated factors in Chinese adults: results from CHNS 1991-2011. J Hypertens 2015;33:1688-96.

19. Zhao LC, Wu YF, Zhou BF, et al. Mean level of blood pressure and rate of hypertension among people with different levels of body mass index and waist circumference. Zhonghua Liu Xing Bing Xue Za Zhi 2003;24:471-5.

20. Gu D, Reynolds K, Wu X, et al. Prevalence, awareness, treatment, and control of hypertension in china. Hypertension 2002;40:920-7.

21. Wu Y, Huxley R, Li L, et al. Prevalence, awareness, treatment, and control of hypertension in China: data from the China National Nutrition and Health Survey 2002. Circulation 2008;118:2679-86.

22. Lewington S, Lacey B, Clarke R, et al. The Burden of Hypertension and Associated Risk for Cardiovascular Mortality in China. Jama Intern Med 2016;176:524-32.

23. Li W, Gu H, Teo KK, et al. Hypertension prevalence, awareness, treatment, and control in 115 rural and urban communities involving 47000 people from China. J Hypertens 2016;34:39-46.

24. Gao Y, Chen G, Tian H, et al. Prevalence of hypertension in china: a cross-sectional study. PLoS One 2013;8:e65938.

25. Wang J, Zhang L, Wang F, et al. Prevalence, awareness, treatment, and control of hypertension in China: results from a national survey. Am J Hypertens 2014;27:1355-61.

26. Zhao L, Yu D, Fu P, et al. Prevalence of hypertension among 18 years old and over adults in 2010-2012 in China: based on the value of mercury sphygmomanometer and 
converted electronic sphygmomanometer. Wei Sheng Yan Jiu 2018;47:7-12.

27. Fang L, Song J, Ma Z, et al. Prevalence and characteristics of hypertension in mainland Chinese adults over decades: a systematic review. J Hum Hypertens 2014;28:649-56.

28. Anchala R, Kannuri NK, Pant H, et al. Hypertension in India: a systematic review and meta-analysis of prevalence, awareness, and control of hypertension. J Hypertens 2014;32:1170-7.

29. Abdul-Razak S, Daher AM, Ramli AS, et al. Prevalence, awareness, treatment, control and socio demographic determinants of hypertension in Malaysian adults. BMC Public Health 2016;16:351.

30. Bhise MD, Patra S. Prevalence and correlates of hypertension in Maharashtra, India: a multilevel analysis. PLoS One 2018;13:e0191948.

31. Nagai M, Ohkubo T, Murakami Y, et al. Secular trends of the impact of overweight and obesity on hypertension in Japan, 1980-2010. Hypertens Res 2015;38:790-5.

32. Kim TJ, Lee JW, Kang HT, et al. Trends in Blood Pressure and Prevalence of Hypertension in Korean Adults Based on the 1998-2014 KNHANES. Yonsei Med J 2018;59:356-65.

33. Malta DC, Santos NB, Perillo RD, et al. Prevalence of high blood pressure measured in the Brazilian population, National Health Survey, 2013. Sao Paulo Med J 2016;134:163-70.

34. Dastan I, Erem A, Cetinkaya V. Awareness, treatment, control of hypertension, and associated factors: results from a Turkish national study. Clin Exp Hypertens 2018;40:90-8.

35. Tailakh A, Evangelista LS, Mentes JC, et al. Hypertension prevalence, awareness, and control in Arab countries: a systematic review. Nurs Health Sci 2014;16:126-30.

36. Naing C, Yeoh PN, Wai VN, et al. Hypertension in Malaysia: an Analysis of Trends from the National Surveys 1996 to 2011. Medicine (Baltimore) 2016;95:e2417.

37. Roy A, Praveen PA, Amarchand R, et al. Changes in hypertension prevalence, awareness, treatment and control rates over 20 years in National Capital Region of India: results from a repeat cross-sectional study. Bmj Open 2017;7:e015639.

38. Souza Filho ZA, Ferreira AA, Santos BD, et al. Hypertension prevalence among indigenous populations in Brazil: a systematic review with meta-analysis. Rev Esc Enferm Usp 2015;49:1016-26.

39. Yang G, Wang Y, Zeng Y, et al. Rapid health transition in China, 1990-2010:findings from the Global Burden of
Disease Study 2010. Lancet 2013;381:1987-2015.

40. Yusufali AM, Khatib R, Islam S, et al. Prevalence, awareness, treatment and control of hypertension in four Middle East countries. J Hypertens 2017;35:1457-64.

41. Eghbali M, Khosravi A, Feizi A, et al. Prevalence, awareness, treatment, control, and risk factors of hypertension among adults: a cross-sectional study in Iran. Epidemiol Health 2018;40:e2018020.

42. Booth JN 3rd, Li J, Zhang L, et al. Trends in Prehypertension and Hypertension Risk Factors in US Adults:1999-2012. Hypertension 2017;70:275-84.

43. Kearney PM, Whelton M, Reynolds K, et al. Global burden of hypertension: analysis of worldwide data. Lancet 2005;365:217-23.

44. Falaschetti E, Chaudhury M, Mindell J, et al. Continued improvement in hypertension management in England: results from the Health Survey for England 2006. Hypertension 2009;53:480-6.

45. Peng $X$. China's demographic history and future challenges. Science 2011;333:581-7.

46. Hu XF, Han XR, Yang ZY, et al. The impact of broadened diagnostic criteria on the prevalence of hypertension, hyperlipidemia and diabetes mellitus in China. Zhonghua Yu Fang Yi Xue Za Zhi 2017;51:369-77.

47. Peng M, Chen G, Kaplan GG, et al. Methods of defining hypertension in electronic medical records: validation against national survey data. J Public Health (Oxf) 2016;38:e392-9.

48. Gong P, Liang S, Carlton EJ, et al. Urbanisation and health in China. Lancet 2012;379:843-52.

49. Spruill TM. Chronic psychosocial stress and hypertension. Curr Hypertens Rep 2010;12:10-6.

50. Jones-Smith JC, Popkin BM. Understanding community context and adult health changes in China: development of an urbanicity scale. Soc Sci Med 2010;71:1436-46.

51. NCD Risk Factor Collaboration (NCD-RisC). Trends in adult body-mass index in 200 countries from 1975 to 2014: a pooled analysis of 1698 population-based measurement studies with 19.2 million participants. Lancet 2016;387:1377-96.

52. Egan BM, Li J, Hutchison FN, et al. Hypertension in the United States, 1999 to 2012: progress toward Healthy People 2020 goals. Circulation 2014;130:1692-9.

53. Feng BY, Chen JC, Li Y, et al. Relationship between overweight/obesity and hypertension among adults in China: a prospective study. Zhonghua Liu Xing Bing Xue Za Zhi 2016;37:606-11.

54. Kuwabara M, Kuwabara R, Niwa K, et al. Different 
Risk for Hypertension, Diabetes, Dyslipidemia, and Hyperuricemia According to Level of Body Mass Index in Japanese and American Subjects. Nutrients 2018;10:1011.

Cite this article as: Bao M, Wang $\mathrm{L}$. The longitudinal trend of hypertension prevalence in Chinese adults from 1959 to 2018: a systematic review and meta-analysis. Ann Palliat Med 2020;9(5):2485-2497. doi: 10.21037/apm-19-377
55. Liu LS. 2010 Chinese guidelines for the management of hypertension. Zhonghua Xin Xue Guan Bing Za Zhi 2011;39:579-615. 